\title{
INFLUÊNCIA DO SUBSTRATO E DO TIPO DE FERTILIZANTE NA ACLIMATAÇÃO DE MUDAS DE BANANEIRA 'PRATA-ANÃ'
}

\author{
Influence of substrate and fertilizer type on the acclimatization of 'Prata-Anã' banana plantlets
}

\author{
Edson Shigueaki Nomura1, Juliana Domingues Lima², Domingos Sávio Rodrigues ${ }^{3}$, \\ Valéria Augusta Garcia ${ }^{4}$, Eduardo Jun Fuzitani ${ }^{5}$
}

\begin{abstract}
RESUMO
Objetivando-se avaliar a influência do substrato e tipo de fertilizante na aclimatação de mudas de bananeira 'Prata-Anã', provenientes de micropropagação, foi instalado um experimento em blocos casualizados, no esquema fatorial $5 \times 3$, com quatro repetições. Os substratos utilizados foram: S1 - Terra de subsolo + casca de arroz carbonizada + substrato comercial Rendimax Floreira $^{\circledR}$; S2 - Terra de subsolo + casca de arroz carbonizada + composto orgânico Organifol ${ }^{\circledR} ; \mathrm{S} 3$ - Terra de subsolo + casca de arroz carbonizada + composto orgânico Organifol ${ }^{\circledR} 9 \%$ SiO; S4 - substrato comercial Technes Vivatto ${ }^{\circledR}$; S5 - Areia grossa + casca de arroz carbonizada + Rendimax Floreira ${ }^{\circledR}$, todos na proporção 1:1:1 (v/v/v). Os fertilizantes utilizados foram: SF - sem fertilizante; FLL fertilizante de liberação lenta, 14-14-14 $\left(5,0 \mathrm{~kg} \mathrm{~m}^{-3}\right)$ misturado ao substrato; e FLN - fertilizante de liberação normal, 14-14-14 (5,0 $\mathrm{kg} \mathrm{m}^{-3}$ ) aplicado em cobertura, 30 dias após o plantio. As mudas foram plantadas em sacos de polietileno quando apresentavam quatro a cinco folhas, sendo mantidas em viveiro com $50 \%$ de sombreamento. Foram feitas medidas de altura, diâmetro do colo e número de folhas, e determinada a massa seca das mudas. As diferenças químicas das misturas utilizadas como substrato, juntamente com o tipo de fertilizante utilizado, proporcionaram crescimento diferenciado das mudas. O substrato S4 pode ser utilizado sem fertilização. Os substratos S2 e S3 devem ser utilizados com fertilizante de liberação normal ou lenta de nutrientes, e S1 e S5, sendo pobres em nutrientes, com fertilizante de liberação lenta.
\end{abstract}

Termos para indexação: Musa spp., crescimento, produção de mudas.

\section{ABSTRACT}

With the aim of evaluating the influence of the substrate and fertilizer type on the acclimatization of plantlets of 'Prata-Anã' banana obtained from micropropagation, a complete randomized block design was installed, in a $5 \times 3$ factorial structure, with four replications. The substrates used were: S1 - subsoil dirt + carbonized rice hull + Rendimax Floreira ${ }^{\circledR}$ commercial substrate; S2 - subsoil dirt + carbonized rice hull + Organifol ${ }^{\circledR}$ organic mixture; S3 - subsoil dirt + carbonized rice hull + Organifol ${ }^{\circledR}$ 9\% SiO organic mixture; S4 - Technes Vivatto ${ }^{\circledR}$ commercial substrate; S5 - thick sand + carbonized rice hull + Rendimax Floreira ${ }^{\circledR}$ commercial substrate, all in proportion 1:1:1 (v:v:v). The fertilizers used were: WF- without fertilizer; FSR - slow-release fertilizer, 14-14-14 $\left(5.0 \mathrm{~kg} \mathrm{~m}^{-3}\right) \mathrm{mixed}^{-3}$ to the substrate; and FNR - normal-release fertilizer, 14-14-14 $\left(5.0 \mathrm{~kg} \mathrm{~m}^{-3}\right)$ applied as top dressing 30 days after the planting. The seedlings were planted in polyethylene bags when they presented four to five leaves, being kept at a nursery with $50 \%$ shading. Height, stem base diameter, and number of leaves were measured and the dry mass of the plantlets was determined. The chemical differences of the mixtures used as substrate, together with the fertilizer type used, resulted in differentiated growth of the plantlets. The S4 substrate may be used without fertilization. The substrate S2 and S3 may be used with fertilizer of normal or slow release of nutrients, and $\mathrm{S} 1$ and $\mathrm{S} 5$, being poor in nutrients, with fertilizer of slow release.

Index terms: Musa spp., growth, plantlet production.

(Recebido em 9 de janeiro de 2008 e aprovado em 28 de agosto de 2008)

\section{INTRODUÇÃO}

Na região do Vale do Ribeira, mudas de bananeira micropropagadas são comercializadas com cerca de cinco a dez centímetros de altura, em bandejas ou raiz nua, necessitando de um período de aclimatação em viveiro sombreado, em recipientes contendo substrato para que alcancem o tamanho adequado para o plantio no campo. Esse processo também pode ser realizado na própria propriedade, reduzindo custos e o estresse das mudas no transporte.

\footnotetext{
'Engenheiro Agrônomo, Pólo Vale do Ribeira - Agência Paulista de Tecnologia dos Agronegócios/APTA - Rodovia Br 116, Km 460, Cx.P. 122 - 11900-000 Registro, SP - edsonnomura@apta.sp.gov.br

'Engenheira Agrônoma, Doutora, Campus Experimental de Registro - Universidade Estadual Paulista/UNESP - Rua Nelson Brihi Badur, 430 - Vila Tupy 11900-000 - Registro, SP - judlima@registro.unesp.br

3Engenheiro Agrônomo, Doutor, Divisão do Jardim Botânico - Seção de Plantas Ornamentais - Secretaria do Meio Ambiente - Instituto de Botânica de São Paulo - Avenida Miguel Stéfano, 3687 - 04302-012 - Água Funda, SP — dsrodrigues@ibot.sp.gov.br

${ }^{4}$ Engenheira Agrônoma, Mestre, Pólo Vale do Ribeira - Agência Paulista de Tecnologia dos Agronegócios /APTA - Rodovia Br 116, Km 460, Cx.P. 122 11900-000 - Registro, SP - valeriagarcia@apta.sp.gov.br

${ }^{5}$ Engenheiro Agrônomo, Pólo Vale do Ribeira - Agência Paulista de Tecnologia dos Agronegócios /APTA - Rodovia Br 116, Km 460, Cx.P. 122 - 11900-000 -

Registro, SP - edufuzitani@apta.sp.gov.br
} 
Poucos trabalhos descrevem com detalhes a aclimatação de mudas de bananeira, havendo carência de informações que relacionem substrato e adubação. A associação de conhecimentos sobre esses fatores podem servir de subsídio para otimização dessa fase do processo de produção de mudas, favorecendo a obtenção de mudas de melhor qualidade, em menor tempo.

O substrato utilizado no recipiente durante a permanência das mudas no viveiro deve apresentar boas características físicas, químicas e biológicas, possibilitando, assim, o rápido crescimento da muda, um bom teor de matéria seca, dentre outras características (YAMANISHI et al., 2004).

Vários materiais podem ser utilizados na composição de substratos, devendo-se levar em consideração as propriedades químicas e físico-hídricas, pois elas influenciam na relação água/ar do substrato e na disponibilidade e absorção de nutrientes (FERNANDES \& CORÁ, 2000).

Os materiais comumente utilizados como substrato para mudas micropropagadas de bananeira incluem palha ou casca de arroz carbonizada, casca curtida de eucalipto ou Pinus, vermiculita, areia, turfa, pó ou moinha de carvão, esterco curtido de curral ou de galinha e terriço (SILVA et al., 1999), sendo que a escolha e a proporção de cada componente varia conforme a disponibilidade na região.

Adicionalmente ao uso do substrato, podem ser feitas adubações que ajudem o desenvolvimento e o crescimento das mudas, além de reduzir os custos de produção pelo menor tempo de permanência no viveiro. A eficiência das adubações em cobertura depende basicamente das doses e fontes dos adubos utilizados, da capacidade de troca catiônica e das características físicas do substrato (SGARBI et al., 1999).

Uma das formas para aumentar a eficiência da adubação é o parcelamento dos nutrientes, principalmente do nitrogênio, porém, essa prática aumenta o custo operacional. Uma alternativa é a utilização de fontes de fertilizante que apresentem liberação lenta ou controlada dos nutrientes (SGARBI et al., 1999), permitindo a disponibilidade contínua, e, portanto, menor possibilidade de deficiência, dispensando aplicações parceladas de outras fontes, reduzindo os custos operacionais (MENDONÇA et al., 2004) e os danos causados pela salinidade do substrato nas mudas (SHARMA, 1979).

Objetivou-se, neste trabalho, avaliar os efeitos de diferentes substratos e tipos de fertilizantes na aclimatação de mudas micropropagadas de bananeira 'Prata-Anã' .

\section{MATERIALE MÉTODOS}

O experimento foi conduzido no Sítio Oriente, localizado na Rodovia Régis Bittencourt, Km 463, no município de Pariquera Açu, SP, sob viveiro telado com $50 \%$ de sombreamento, com irrigação por sistema de microaspersão.

A cultivar de bananeira utilizada foi a Prata-Anã, sendo as mudas micropropagadas no laboratório da Agência Paulista de Tecnologia dos Agronegócios, APTA. $\mathrm{Na}$ ocasião do plantio, as mudas apresentavam cerca de cinco centímetros de altura, quatro a cinco folhas e raiz nua, sendo plantadas em sacos de polietileno, contendo 1,5 litros de substrato. Os sacos foram colocados sobre o solo coberto com filme de polietileno preto, mantendo-se o espaçamento de $20 \mathrm{~cm}$ entre os mesmos.

O delineamento experimental foi em blocos ao acaso, em esquema fatorial 5 x 3, com quatro repetições, sendo cada unidade experimental constituída de quatro mudas. Os substratos utilizados foram: S1 - Terra de subsolo + casca de arroz carbonizada + substrato comercial Rendimax Floreira $^{\circledR} ;$ S2 - Terra de subsolo + casca de arroz carbonizada + composto orgânico Organifol ${ }^{\circledR} ;$ S3 - Terra de subsolo + casca de arroz carbonizada + composto orgânico Organifol ${ }^{\circledR}$ 9\% SiO; S4 - Technes Vivatto ${ }^{\circledR}$ S5 - Areia grossa + casca de arroz carbonizada + substrato comercial Rendimax Floreira $^{\circledR}$. Todas as misturas foram preparadas na proporção 1:1:1 (v/v/v). Os fertilizantes utilizados foram: SF - sem fertilizante; FLL - fertilizante de liberação lenta (controlada) - Osmocote ${ }^{\circledR} 3 \mathrm{M}, 14-14-14\left(5,0 \mathrm{~kg} \mathrm{~m}^{-3}\right)$ misturado ao substrato; e FLN - fertilizante de liberação normal (não controlada), granulado 14-14-14 (5,0 $\left.\mathrm{kg} \mathrm{m}^{-3}\right)$, aplicado em cobertura 30 dias após o plantio. No preparo dos substratos foram retiradas amostras para análise química.

Semanalmente, foram feitas medidas da altura e diâmetro do colo das mudas. Aos sessenta e três dias após o plantio, também foram determinados o número de folhas e a massa seca da parte aérea (MSPA) e da raiz (MSR) das mudas, após a secagem em estufa a $70^{\circ} \mathrm{C}$, até peso constante.

Os dados foram submetidos à análise da variância e as médias dos fatores comparadas pelo teste de Tukey, a $5 \%$ de probabilidade. Para avaliar o incremento na altura e no diâmetro do colo das mudas foram realizados ajustes de funções de regressão.

\section{RESULTADOS E DISCUSSÃO}

A análise química dos substratos mostrou diferenças nos teores de alguns nutrientes, com destaque para os substratos S2, S3 e S4 que apresentaram teores mais elevados de nutrientes, principalmente N, K, Ca e S (Tabela 1).

Mudas cultivadas nos substratos S1, S2, S3 e S4 foram as que apresentaram maior número de folhas e as cultivadas em S5, o menor número de folhas (Tabela 2). Não houve diferenças no número de folhas das mudas 
cultivadas nos substratos que receberam FLL e FLN, que diferiram das mudas cultivadas SF. O menor número de folhas observado em mudas cultivadas em S5 pode ser atribuído ao baixo teor $\mathrm{N}\left(\mathrm{NO}_{3}^{-}+\mathrm{NH}_{4}\right)$, que segundo Moreira (1987), juntamente com o K, são os nutrientes que mais influenciam o número de folhas.

Para os substratos S1 e S5, houve maior crescimento em altura nas mudas cultivadas com FLL, seguida de mudas cultivadas FLN e por último de mudas cultivadas SF (Figura 1), sendo que, aos 63 dias após o plantio, essas diferenças foram significativas (dados não apresentados). Contudo, para os substratos S2, S3 e S4, não se verificaram diferenças significativas na altura de mudas que receberam FLL e FLN (dados não apresentados). Essas respostas, provavelmente, decorrem do fato dos substratos S1 e S5 terem apresentado teores mais baixos de N e K. Portanto, a aplicação do FLL foi capaz de suprir as necessidades desses nutrientes de maneira mais adequada que o FLN.

Para o diâmetro do colo das plantas, os resultados apresentados na Figura 2, mostram a mesma tendência apresentada para o crescimento em altura, ou seja, plantas cultivadas nos substratos S1 e S5 aos 63 dias após o plantio apresentaram diferenças significativas no diâmetro do colo entre plantas que receberam FLL e FLN (dados não apresentados). Já nos substratos S2, S3 e S4, essas diferenças não ocorreram. No $S 4$, inclusive não houve diferenças entre as mudas dos tratamentos SF, FLL e FLN (Figura 2), mesma tendência apresentada para altura das plantas (Figura 1).

Beugmon \& Champion (1966), citados por Santos et al. (2004) relacionaram o diâmetro do pseudocaule com o número de raízes. Dessa forma, espera-se que mudas com diâmetro de colo superior originem plantas com sistema radicular maior, aumentando a porcentagem de pegamento no campo e velocidade do desenvolvimento inicial.

A massa seca da parte aérea não diferiu significativamente entre os substratos quando se utilizou FLL (Tabela 3). Já com o uso do FLN, plantas nos substratos S2, S3, S4 e S5 não diferiram entre si e foram superiores ao S1.

$\mathrm{O}$ acúmulo de massa seca na raiz variou nas mudas dos diferentes substratos (Tabela 3). Em relação aos tipos de fertilizantes, o maior acúmulo ocorreu em plantas que receberam FLL, não havendo diferenças entre mudas cultivadas SF e FLN.

O substrato comercial Technes Vivatto ${ }^{\circledR}$ (S4) supriu as necessidades nutricionais das mudas no período de aclimatação, indicando a possibilidade de descartar adubação quando o mesmo for utilizado (Tabelas 2 e 3, Figuras 1 e 2).

Tabela 1 - Teores de nutrientes e pH dos substratos testados antes da adubação química. Centro de Solos e Recursos Agroambientais. Laboratório de Análise de Solo e Planta, IAC. Campinas, 2006.

\begin{tabular}{|c|c|c|c|c|c|c|c|c|c|c|c|c|c|}
\hline & $\mathrm{NO}_{3}^{-}$ & $\mathrm{NH}_{3}$ & $\mathrm{P}$ & $S$ & $\mathrm{~K}$ & $\mathrm{Ca}$ & $\mathrm{Mg}$ & $B$ & $\mathrm{Cu}$ & $\mathrm{Fe}$ & $\mathrm{Mn}$ & $\mathrm{Zn}$ & $\mathrm{pH}$ \\
\hline \multicolumn{14}{|c|}{$\left(\mathrm{mg} \mathrm{L}^{-1}\right)$} \\
\hline S1 & 1,9 & 1,73 & 0,04 & 42,2 & 51,4 & 25,7 & 16,8 & 0,08 & 0,01 & 0,03 & 0,04 & 0,03 & 4,6 \\
\hline S2 & 12,8 & 0,01 & 0,34 & 110,0 & 214,1 & 55,1 & 25,9 & 0,13 & 0,02 & 0,02 & 0,29 & 0,12 & 6,0 \\
\hline S3 & 83,2 & 0,69 & 0,32 & 156,0 & 209,2 & 134,3 & 50,5 & 0,14 & 0,03 & 0,03 & 0,12 & 0,04 & 5,5 \\
\hline S4 & 212,7 & 2,07 & 0,42 & 337,0 & 267,6 & 306,6 & 76,2 & 1,73 & 0,02 & 0,04 & 0,34 & 0,12 & 5,0 \\
\hline S5 & 0,2 & 1,86 & 1,49 & 27,9 & 53,5 & 16,4 & 13,5 & 0,08 & 0,04 & 1,08 & 0,71 & 0,04 & 4,9 \\
\hline
\end{tabular}

Método de extração: 1:1,5 (Holanda). Métodos de determinação: N-(amoniacal e nitrato): destilação; K, Ca, Mg, P, S, Cu, Fe, Mn, Zn: ICP-OES; C orgânico: Walkley-Black.

Tabela 2 - Número de folhas em função dos substratos e fertilizantes em mudas de bananeira 'Prata-Anã', aos 63 dias de aclimatação. Pariquera Açu, SP, 2006.

\begin{tabular}{ccccccccc}
\hline & \multicolumn{2}{c}{ SF } & \multicolumn{2}{c}{ FLL } & \multicolumn{2}{c}{ FLN } & \multicolumn{2}{c}{ Médias } \\
\hline S1 & 5,75 & b A & 5,25 & b B & 7,00 & a A & 6,00 & AB \\
S2 & 6,50 & a A & 6,00 & a AB & 6,25 & a A & 6,25 & A \\
S3 & 6,50 & a A & 6,50 & a A & 6,25 & a A & 6,42 & A \\
S4 & 6,00 & a A & 6,75 & a A & 7,00 & a A & 6,58 & A \\
S5 & 3,75 & b B & 6,50 & a A & 6,25 & a A & 5,50 & C \\
\hline Médias & 5,70 & b & 6,20 & a & 6,55 & a & & \\
\hline
\end{tabular}

Médias seguidas da mesma letra maiúscula na coluna e da mesma letra minúscula na linha, não diferem entre si, a 5\% de probabilidade pelo teste de Tukey. 

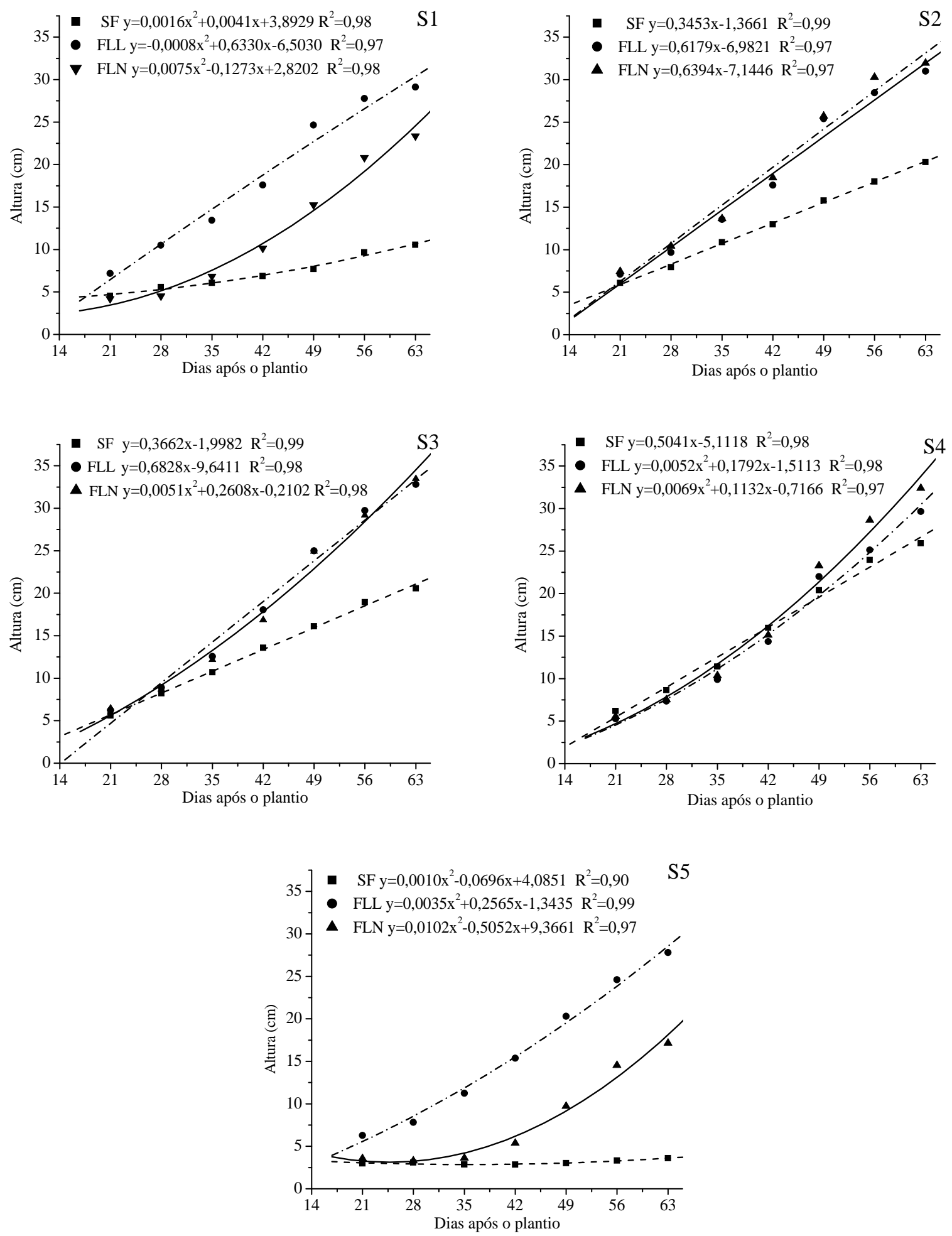

Figura 1 - Altura média de mudas de bananeira 'Prata-Anã' em função dos fertilizantes: SF (sem fertilizante), FLL (fertilizante de liberação lenta) e FLN (fertilizante de liberação normal), e do tipo de substrato. 

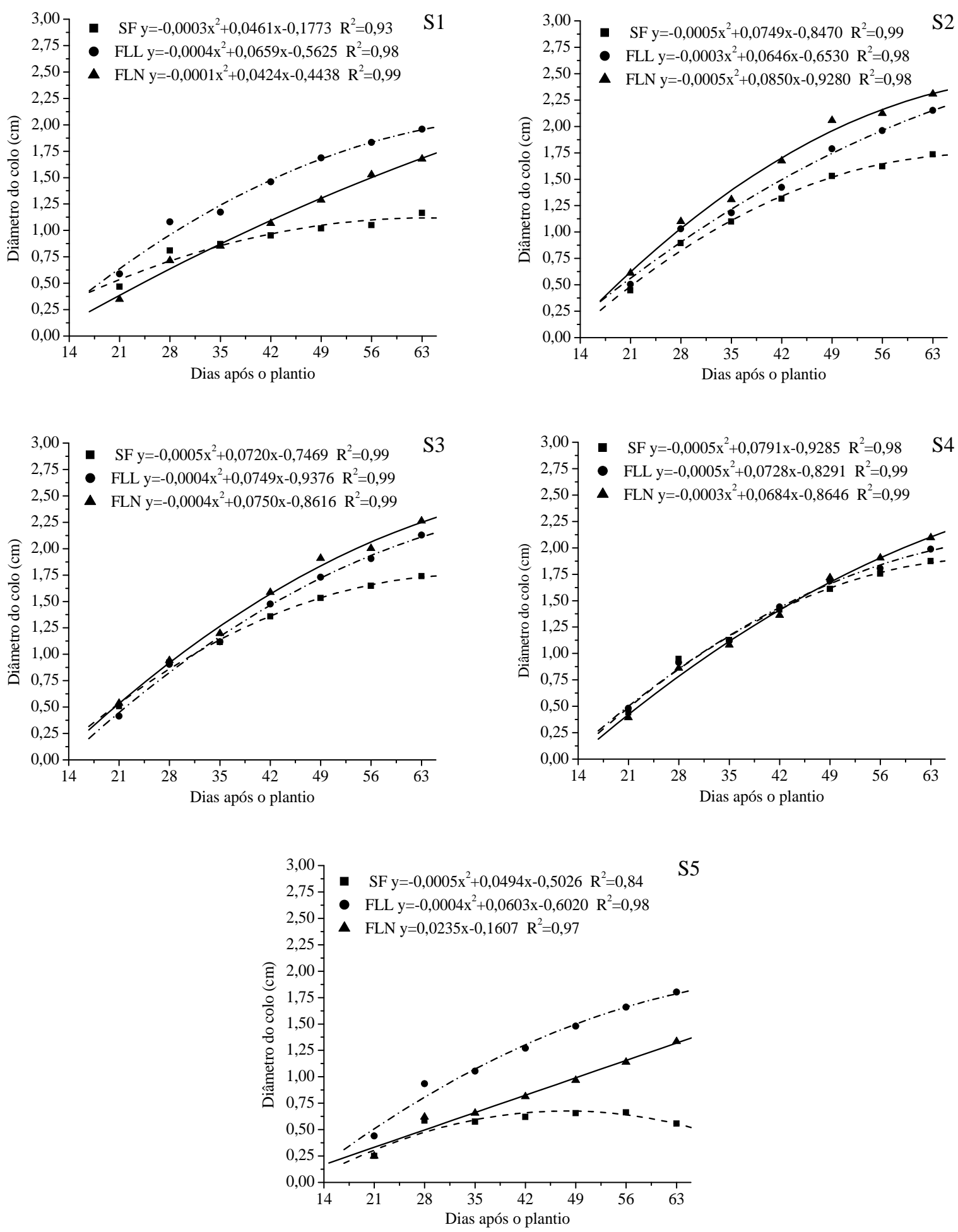

Figura 2 - Diâmetro do colo de mudas de bananeira 'Prata-Anã' em função dos fertilizantes: SF (sem fertilizante), FLL (fertilizante de liberação lenta) e FLN (fertilizante de liberação normal), e do tipo de substrato. 
Tabela 3 - Massa seca da parte aérea (MSPA) e da raiz (MSR) em função dos substratos e fertilizantes, em mudas de bananeira 'Prata-Anã', aos 63 dias de aclimatação. Pariquera Açu, SP, 2006.

\begin{tabular}{|c|c|c|c|c|c|c|}
\hline & \multicolumn{2}{|c|}{ SF } & \multicolumn{2}{|c|}{ FLL } & \multicolumn{2}{|c|}{ FLN } \\
\hline & MSPA (g) & MSR (g) & MSPA (g) & MSR (g) & MSPA (g) & MSR (g) \\
\hline S1 & 1,99 b BC & $1,17 \mathrm{~b}$ BC & 7,41 a $\mathrm{A}$ & 4,03 a A & 5,32 a B & $2,11 \mathrm{~b} \quad \mathrm{AB}$ \\
\hline $\mathrm{S} 2$ & $7,09 \mathrm{~b} \mathrm{~A}$ & 2,89 a A & $8,33 \mathrm{abA}$ & 2,76 a $\mathrm{AB}$ & 10,52 a $\mathrm{A}$ & 3,55 a $A$ \\
\hline S3 & $5,44 \mathrm{~b} A B$ & 2,30 a $A B$ & $8,21 \mathrm{abA}$ & 2,46 a B & 9,93 a $\mathrm{A}$ & 2,45 a $A B$ \\
\hline S4 & 8,88 a $A$ & 1,86 a $\mathrm{ABC}$ & 9,97 a $\mathrm{A}$ & 2,31 a B & $9,12 \mathrm{a} \mathrm{A}$ & 1,89 a $B$ \\
\hline S5 & $0,63 \mathrm{~b} \mathrm{C}$ & $0,45 \mathrm{~b} \mathrm{C}$ & 7,69 a A & 2,03 a B & $3,12 \mathrm{~b} \mathrm{~B}$ & $1,00 \mathrm{ab} B$ \\
\hline
\end{tabular}

Médias seguidas da mesma letra maiúscula na coluna e da mesma letra minúscula na linha, não diferem entre si, a 5\% de probabilidade pelo teste de Tukey.

Nos substratos S2 e S3, considerados de fertilidade mediana conforme a análise química (Tabela 1), as diferenças no crescimento foram pequenas ou nulas nas mudas que receberam FLL e FLN. Isso sugere que, para esses substratos, a adubação é necessária, sendo possível a utilização dos dois tipos de fertilizantes.

Para os substratos com baixos teores de nutrientes (S1 e S5) (Tabela 1), o FLL teve maior influência no crescimento das mudas, quando comparado com o FLN. Segundo Huett (1997), um dos benefícios da utilização desse tipo de fertilizante em relação à utilização de fertilizantes solúveis é a baixa perda de nutrientes por lixiviação. Assim, as diferenças no crescimento das mudas podem ser explicadas também pela disponibilidade mais contínua dos nutrientes, uma vez que FLL foi adicionado no preparo do substrato, enquanto o FLN aplicado 30 dias após o plantio das mudas.

Em diversos trabalhos, os efeitos benéficos do uso do Osmocote ${ }^{\circledR}$ foram evidenciados. Oliveira et al. (1995), observaram mudas de cafeeiro mantidas em Plantmax ${ }^{\circledR}$ fertilizado com Osmocote ${ }^{\circledR}$ (17-09-13) apresentaram maior altura, vigor, qualidade e sanidade, além da antecipação de 40 dias na liberação das mesmas, com economia de mãode-obra. Andrade Neto et al. (1999) verificaram também maior crescimento de mudas de cafeeiro quando ao esterco de curral foi adicionado Osmocote ${ }^{\circledR}$. Nomura et al. (2008) verificaram que, mudas micropropagadas de bananeira 'Nanicão', aclimatadas em substrato pobre em nutrientes, acrescido de fertilizante de liberação lenta apresentaram maiores valores de crescimento em altura, diâmetro do colo e massa seca da parte aérea, quando comparadas com mudas que receberam fertilizante de liberação normal de nutrientes aclimatadas no mesmo substrato.

Além das características químicas, físicas e biológicas do substrato, também deve ser observada a disponibilidade dos seus materiais constituintes. Sousa et al. (2000) verificaram que o substrato constituído por 250 $\mathrm{ml} \mathrm{L}^{-1}$ de Latossolo vermelho amarelo húmico, $150 \mathrm{ml} \mathrm{L}^{-1} \mathrm{de}$ areia lavada, $450 \mathrm{ml} \mathrm{L}^{-1}$ de esterco de galinha e $150 \mathrm{ml} \mathrm{L}^{-1} \mathrm{de}$ casca de arroz carbonizada proporcionou a obtenção de mudas de bananeira 'Mysore' com crescimento, acúmulo de matéria fresca e estado nutricional superior. No Vale do Ribeira, existe boa disponibilidade de casca de arroz carbonizada, que foi utilizada na composição em quatro dos cinco substratos testados no presente estudo. Além de ser um material adequado para composição de substratos por permitir boa aeração e drenagem, a casca de arroz carbonizada apresenta volume constante e é livre de plantas daninhas, nematóides e patógenos (SOUSA et al., 2000).

As diferenças químicas nas misturas utilizadas como substrato e a fertilização suplementar proporcionaram crescimento diferenciado nas mudas de bananeira 'PrataAnã', durante a aclimatação. Todas as misturas testadas podem ser recomendadas, sendo que o teor de nutrientes da mistura deve indicar a necessidade de adubação e o tipo de fertilizante mais adequado.

\section{CONCLUSÕES}

O substrato comercial Technes Vivatto ${ }^{\circledR}$, sem adição de fertilizante, promove bom desenvolvimento de mudas micropropagadas de bananeira 'Prata-Anã', na fase de aclimatação;

Os substratos constituídos por terra de subsolo + casca de arroz carbonizada + composto orgânico Organifol ${ }^{\circledR}$ com ou sem sílica podem ser recomendados com fertilizantes de liberação normal ou lenta;

Os substratos, terra de subsolo + casca de arroz carbonizada + substrato comercial Rendimax Floreira ${ }^{\circledR}$ ou areia grossa + casca de arroz + substrato comercial Rendimax Floreira ${ }^{\circledR}$, devem ser recomendados associados 
com fertilizante de liberação lenta, para aclimatação de mudas micropropagadas de 'Prata-Anã'.

\section{REFERÊNCIAS BIBLIOGRÁFICAS}

ANDRADE NETO, A. de; MENDES, M. A. N. G.; GUIMARÃES, P. T. G. Avaliação de substratos alternativos e tipos de adubação para a produção de mudas de cafeeiro (Coffea arabica L.) em tubetes. Ciência e Agrotecnologia, Lavras, v. 23, n. 2, p. 270-280, 1999.

FERNANDES, C.; CORÁ, J. E. Caracterização físicohídrica de substratos utilizados na produção de mudas de espécies olerícolas e florestais. Horticultura Brasileira, Brasília, v. 18, p. 469-471, 2000. Suplemento.

HUETT, O. O. Fertilizer use efficienty by containerized nursery plants: 2. nutrient leaching. Australian Journal Agriculture Researse, Melbourne, v. 48, p. 251-258, 1997.

MENDONÇA, V.; RAMOS, J. D.; GONTIJO, T. C. A.; MARTINS, P. C. C.; DANTAS, D. J.; PIO, R.; ABREU, N. A. A. Osmocote ${ }^{\circledR}$ e substratos alternativos na produção de mudas de maracujazeiro-amarelo. Ciência e Agrotecnologia, Lavras, v. 28, n. 4, p. 799-806, 2004.

MOREIRA, R. S. Banana: teoria e prática e prática de cultivo. Campinas: Fundação Cargill, 1987. 335 p.

NOMURA, E. S.; LIMA, J. D.; GARCIA, V. A.; RODRIGUES, D. S. Crescimento de mudas micropropagadas da bananeira cv. Nanicão, em diferentes substratos e fontes de fertilizante. Acta Scientiarum Agronomy, Maringá, v. 30, n. 3, p. 359-363, 2008.

OLIVEIRA, P. S. R.; GUALBERTO, R.; FAVORETO, A. J. Efeito do Osmocote adicionado ao substrato Plantmax na produção de mudas de café em tubetes. In:
CONGRESSO BRASILEIRO DE PESQUISAS

CAFEEIRAS, 21., 1995, Caxambu, MG. Anais... Caxambu: PROCAFE/DENAC, 1995. p. 70-72.

SANTOS, J. de A. dos; SILVA, C. R. de R. e; CARVALHO, J. G. de; NASCIMENTO, T. B. do. Efeito do calcário dolomítico e nitrato de potássio no desenvolvimento inicial de mudas da bananeira 'PrataAnã' (AAB), provenientes de cultura in vitro. Revista Brasileira de Fruticultura, Jaboticabal, v. 26, n. 1, p. 150-154, 2004.

SGARBI, F.; SILVEIRA, R. V. A.; HIGASHI, E. N.; PAULA, T. A. e; MOREIRA, A.; RIBEIRO, F. A. Influência da aplicação de fertilizante de liberação controlada na produção de mudas de um clone de Eucalyptus urophylla. In: SIMPÓSIO SOBRE FERTILIZAÇÃO E NUTRIÇÃO FLORESTAL, 2., 1999, Piracicaba, SP. Anais... Piracicaba: IPEF-ESALQ, 1999. p. 120-125.

SHARMA, G. C. Controlled-release fertilizers and horticultural applications. Scientia Horticulturae, Alabama, v. 11, n. 2, p. 107-129, 1979.

SILVA, D. S.; BOSISIO, A.; BOSCAROL, B.; BELTZER, A.; AMSLER, G. P. Aclimatação de mudas de bananeira (Musa spp.) 'Prata' (AAB) em diferentes substratos. Revista Ceres, Viçosa, v. 46, n. 267, p. 543-554, 1999.

SOUSA, H. U.; SILVA, C. R. R.; CARVALHO, J. G.; MENEGUCCI, J. L. P. Nutrição de mudas de bananeira em função de substratos e doses de superfosfato simples. Ciência e Agrotecnologia, Lavras, v. 24, p. 64$73,2000$.

YAMANISHI, O. K.; FAGUNDES, G. R.; MACHADO FILHO, J. A.; VALONE, G. V. Efeito de diferentes substratos e duas formas de adubação na produção de mudas de mamoeiro. Revista Brasileira de Fruticultura, Jaboticabal, v. 26, n. 2, p. 276-279, 2004. 